\title{
Princípio Democrático e Administração Pública Democrática em Tempos de Cibercidadania
}

\begin{abstract}
Caio Sperandéo de Macedo
Pós-doutorando da Faculdade de Direito da Universidade de Lisboa-Portugal (Fdul). Especialização em Ciências Jurídico-Políticas Doutorado em Filosofia do Direito pela Pontifícia Universidade Católica de São Paulo (PUC/SP, 2014). Mestrado em Direito do Estado pela Pontifícia Universidade Católica de São Paulo (2005). Graduação em Direito pela Pontifícia Universidade Católica de São Paulo (1996). Parecerista ad hoc da Revista Jurídica da Presidência - Centro de Estudos Jurídicos da Presidência (ISSN: 2236-3645). Professor da Graduação do Curso de Direito da Universidade Mogi das Cruzes (UMC), campus Villa Lobos, São Paulo. Advogado com atuação na área de Direito Empresarial, Educacional, educação superior brasileira e sociedade da informação. http://lattes.cnpq. br/5246795808445782. https://orcid.org/0000-0002-3812-8806. caio.csm@terra.com.br
\end{abstract}

\section{RESUMO}

O conceito dinâmico do princípio democrático na Constituição da República Federativa do Brasil de 1988 espraia seus efeitos axiológicos para outras prescrições normativas que enaltecem a participação do cidadão na administração pública para exigir dos órgãos oficiais que a veiculação de informações e dados de interesse particular, de interesse coletivo ou de interesse público em geral, sejam disponibilizados pela Internet a fim de permitir não somente acessibilidade à informação, mas, também, conhecimento funcional e controle dos atos praticados por quem exerce poderes em nome do Estado. Alertar que embora a incorporação das novas tecnologias da informação e da comunicação à infraestrutura seja indispensável à modernização do Estado contemporâneo, revela-se fundamental no caso brasileiro fomentar os mecanismos de participação democrática por meio do sistema educacional a fim de superar a falta de confiança da sociedade na administração pública.

Palavras-chave: Princípio democrático. Administração pública democrática. Sociedade da informação. Cibercidadania.

\section{DEMOCRATIC PRINCIPLE AND PUBLIC DEMOCRATIC ADMINISTRATION IN TIMES OF CIBER-CITIZENSHIP}

\section{ABSTRACT}

The dynamic concept of the democratic principle in the Constitution of the Federative Republic of Brazil of 1988 expands its axiological effects to other normative prescriptions that exalt the participation of the citizen in the public administration to demand from the official bodies that the transmission of information and data of particular interest, of collective interest or of public interest in general, are made available on the Internet in order to allow not only access to information, but also functional knowledge and control of acts practiced by those who exercise powers in name of State. Alert that although the incorporation of new information and communication technologies into infrastructure is indispensable for the modernization of the contemporary state, it is fundamental in the Brazilian case to foment the mechanisms of democratic participation through the educational system in order to overcome society's lack of trust in public administration.

Keywords: Democratic principle. Public democratic administration. Information society. Cybercitizenship. SUMÁRIO

1 Introdução. 2 Princípio Democrático e Democracia Participativa na Constituição Federal de 1988. 3 Direito de Participar e Fiscalizar os Negócios do Estado Democrático na Sociedade da Informação. 4 Possibilidades de Participação Democrática do Cidadão no Ambiente Digital. 5 Cibercidadania e a Participação Democrática no Estado Brasileiro. 6 Conclusão. 7 Referências. 


\section{INTRODUÇÃO}

O princípio democrático encontra-se albergado com destaque na Constituição Federal de 1988 e seu conteúdo dinâmico irradia efeitos axiológicos para diversos dispositivos constitucionais complementares que conferem direitos e deveres aos cidadãos, com destaque nesta abordagem para os ligados à disponibilização pela administração pública de informações relacionadas aos registros administrativos, licitações, contratos e demais atos de governo e também o direito dos cidadãos em receber dos órgãos públicos informações de seu interesse particular, ou de interesse coletivo ou geral.

Entende-se que o acesso a registros administrativos, dados e demais informações relativas à atuação do governo e principalmente a destinação e boa aplicação de recursos do patrimônio público devem permanecer disponíveis e acessáveis para consulta dos cidadãos, a fim de que tomem consciência das ações e decisões políticas envidadas pelo Estado, fiscalizem a aplicação de recursos públicos e participem no aperfeiçoamento do seu funcionamento na condição de cidadãos, em prol da sociedade.

Estas formas de participação do cidadão na administração pública ganharam novo relevo neste início de século 21 não somente em virtude do desenvolvimento cívico da sociedade, mas, sobretudo, em decorrência da indelével inserção das novas tecnologias da comunicação e da informação na infraestrutura dos órgãos e funcionamento da administração pública.

Estas tecnologias ínsitas à sociedade da informação, que comportam facilidade de acesso, armazenagem e acompanhamento de informações, conjugadas com velocidade em tempo real de propagação da comunicação por meio de redes digitais têm o poder de criar o que se pode denominar de cibercidadania; conceito que pressupõe um instrumental tecnológico disponível apto a incrementar as possiblidades de participação e verificação de desempenho (eficiência) e moralidade das funções administrativas do governo por parte dos cidadãos cônscios de seus direitos.

Adota-se neste estudo como ponto de partida o texto constitucional de 1988 a fim de analisar o tema dentro de uma perspectiva normativa e sociológica. Assim, não é objeto do trabalho os pormenores da legislação infraconstitucional, embora algumas considerações a respeito far-se-ão necessárias para demonstrar a modernização das formas de atuação da administração pública. Em uma dimensão de direitos fundamentais, enaltecer o conteúdo valorativo do princípio democrático para exercício de direitos ligados à participação do cidadão no Estado, direito de analisar as decisões político-administrativas do Estado potencializado pela amplitude e acesso ao fluxo de informações que trafega na via digital.

É preciso reconhecer que estamos diante de uma realidade cultural em transformação neste início de século 21, que o ambiente digital pode incrementar o capital social dos cidadãos e impõe uma reconfiguração do papel do Estado para instaurar administração pública democrática e eficiente na prestação de serviços públicos; que respeite a publicidade dos atos oficiais, que valorize a colaboração do cidadão, a transparência de sua atuação, que preste contas da sua gestão e que cobre responsabilidade em todos os níveis de governo. 
Justifica-se a escolha temática em razão do desenvolvimento recente das novas Tecnologias da Comunicação e da Informação (TICS) nos mecanismos de atuação da administração pública brasileira e amparados em legislação infraconstitucional correlata, mormente diante de seu caráter democrático vinculado à valorização da participação e do acompanhamento do cidadão com relação à atuação do Estado, em prol de uma democracia administrativa.

Em termos de pesquisa científica observou-se durante o trabalho o método indutivo partindo-se da indelével premissa democrática da Constituição Federal de 1988 e sua interpretação doutrinária (bibliográfica), problematizando sua aplicação empírica por meio de uma legislação voltada para a utilização do ambiente digital pela administração pública para divulgação e o acesso a informações de interesse público com o objetivo de permitir maior controle e participação dos cidadãos sobre a atuação dos órgãos estatais, contexto que emerge com força crítica com relação ao funcionamento do Estado contemporâneo, o comportamento dos administradores públicos, das instituições e a participação dos cidadãos.

\section{PRINCÍPIO DEMOCRÁTICO E DEMOCRACIA PARTICIPATIVA NA CONSTITUIÇÃO FEDERAL DE 1988}

Em comentário à Constituição Federal de 1988, José Afonso da Silva (2008, p. 40) esclarece que o princípio democrático não é um "valor-fim", embora seu conceito revele um poder político que se fundamenta na vontade popular (justificado politicamente em uma soberania popular) como instrumento de afirmação de direitos e garantias conquistadas, mantenedor das liberdades públicas e do regime democrático.

Além disso, como princípio estruturante previsto no artigo 10 caput da Constituição Federal de 1988, o princípio democrático enaltece o Estado de Direito e também alberga em seu conteúdo a ideia de democracia representativa, que combinada com o exercício da cidadania abre espaço para o desenvolvimento de uma democracia participativa (artigo 1ำ, parágrafo único).

Ao seguir este raciocínio, pode-se dizer que os contornos da democracia participativa caracterizam-se pela maior possibilidade de colaboração direta na formação da vontade dos atos de governo, notadamente pelos institutos previstos para democracias semidiretas como a brasileira, que combinam instrumentos de participação direta (como a iniciativa popular; referendo e o plebiscito), bem como outras possibilidades previstas de atuação pessoal como revelam, por exemplo, artigos 10, 11, 31§3ㅇ, 74 §2ㅇ, 194, VII, 206, VI e 216,§1으 (DA SILVA, 2008, p. 41).

Assim sendo, nesta linha de atuação que a Constituição Federal de 1988 encampou a cláusula democrática (artigo 1ํ, §único, C.F.) e em outros dispositivos que lhe são auxiliares e que fazem parte do núcleo que the garante identidade e por isso também irradiam seus efeitos para todo o texto constitucional, como o princípio federativo, o republicano, o da separação dos poderes, o da cidadania, etc. Ou seja, em nossa Carta constitucional vigente a soberania popular tem por escopo funcionar como garantidora das decisões políticas fundamentais. 
Isso posto, pode-se afirmar que o princípio democrático funciona como vetor axiológico no sentido atribuído por Robert Alexy (2014, p. 145), apto para legitimar também as modalidades objetivas previstas para o cidadão participar no Estado (e.g. artigos 50, XXXIII, 29, 37, $\S 3$ - C.F.), e para balizar o funcionamento da administração pública e a conduta de seus servidores (artigo 37, C.F.).

Entrementes, consoante o rol dos direitos fundamentais de primeira, segunda e terceira dimensões calcados respectivamente na tríade liberdade, igualdade e fraternidade, Paulo Bonavides (2005, p. 570) reconhece que o processo de globalização econômica e sociocultural em que estamos imersos faz surgir na agenda política os direitos fundamentais de quarta dimensão como a última fase de institucionalização do Estado social.

Nesta quarta dimensão fundamental estaria o direito à democracia, o direito à informação e o direito ao pluralismo de ideias e concepções, ressalvando Paulo Bonavides que tais valores só podem ascender caso a informação e pluralismo sejam efetivos e funcionem como auxiliares da democracia.

Paulo Bonavides (2005, p. 570) enfatiza que a concretização desta última dimensão de direitos em uma democracia contemporânea recai sobre os cidadãos mais bem informados sobre os negócios e funcionamento do Estado e cônscios de seus direitos de participação a fim de colaborar e se envolver com atos e decisões adotados pela administração pública.

Em consonância com esta perspectiva nos últimos anos as sociedades democráticas têm encampado demandas sociais em prol da cidadania para resgatar a essência da res publica, ou seja, o exercício de direitos de ter conhecimento e ser partícipe nas decisões do Estado, em prol do interesse público.

O princípio democrático, portanto, revela-se de forma mais abrangente do que sugerem as previsões constitucionais ao buscar desenvolver e aperfeiçoar mecanismos para o cidadão colaborar em um processo plural e inclusivo a partir do qual se constroem as vontades e opiniões políticas mediante o exercício dos direitos subjetivos de participação (SWENSSON JR., 2018, p. 48).

Mormente no contexto da sociedade da informação e por corolário da inserção das novas tecnologias da comunicação no ambiente cultural do século 21 , vez que o acesso e a obrigatoriedade de disponibilidade de dados que trafegam nas vias digitais telemáticas com relação à administração pública (Internet, redes sociais, telefones celulares em rede, sites, correio eletrônico, etc.), aliada à velocidade do fluxo de informações veiculadas pelas mídias permite criar novas relações sociais e institucionais no espaço digital para os cidadãos debaterem ideias, experiências, e aderir ou não a projetos individuais, coletivos e institucionais (FIORILLO, 2015, p. 124).

Diante de uma realidade social e cultural em transformação, inegável reconhecer que a sociedade está a exigir e a tecnologia disponível comporta uma modernização da forma de atuação da administração pública para dar cobro aos seus compromissos democráticos, os quais podem ser exemplificados de forma não exaustiva em: dar publicidade no exercício de funções administrativas, digitalizar e disponibilizar pela Internet todas as informações públicas e de interesse público lato sensu; dar transparência à condução aos projetos e executá-los 
com competência e probidade, notadamente quanto à oferta de serviços públicos de qualidade; estabelecer canais de comunicação institucionais efetivos e diretos com a sociedade voltados para participação, acompanhamento e gestão de recursos e de prestação de contas.

Nesse contexto, a participação política do indivíduo nos desígnios do Estado decorre exatamente da maior acessibilidade às informações de interesse público possibilitada pelas novas tecnologias da informação conjugada a um sentimento de pertença de que o Estado não é um fim em si mesmo; tem por missão defender o interesse público e possibilitar bem-estar ao cidadão.

\section{DIREITO DE PARTICIPAR E FISCALIZAR OS NEGÓCIOS DO ESTADO DEMOCRÁ- TICO NA SOCIEDADE DA INFORMAÇÃO}

A Constituição Federal de 1988, além de consagrar o Estado Democrático de Direito e a forma republicana de governo, acolhe basicamente duas formas de colaboração dos cidadãos na conformação do Estado: (i) a participação na administração pública direta e indireta e (ii) a participação direta no processo político nas hipóteses previstas (e.g. artigo 14, I, II e III, C.F.).

Ao que nos toca a abordagem concentra-se na primeira hipótese, na possibilidade de participação funcional do cidadão na administração pública, inclusive por meio do livre acesso a registros administrativos e informações sobre atos de governo, artigo 37, §3ㅇ, inciso II, combinado com artigo 5으, XXXIII, o qual assegura a todos transparência no direito de receber dos órgãos públicos informações de seu interesse particular ou de interesse coletivo ou geral, que devem ser prestadas na forma da Lei n. 12.527/2011 (Lei de Acesso à Informação).

Entende-se que o amplo acesso às informações de interesse particular, geral e de interesse público relacionado a registros administrativos e dados sobre atos de governo fortalece o interesse cívico para colaborar com a administração pública e se revela fundamental para o aperfeiçoamento dos mecanismos operativos do Estado Democrático.

Notadamente porque guarda relação de dependência com o princípio democrático (e com o regime republicano) calcado na preservação do interesse público e na possibilidade de fiscalização complementar direta pelos cidadãos com relação às decisões políticas e aos recursos aplicados por todas as esferas da administração pública (federal, estadual e municipal), não obstante preservados os normais mecanismos de controle interno e externo previstos institucionalmente, como a Controladoria Geral da União (CGU) e os Tribunais de Contas.

Entrementes, vale observar que há ampla previsão na Constituição Federal de 1988 compilada por José Afonso da Silva (2003, p. 104) com relação às modalidades objetivas de o cidadão participar no aperfeiçoamento da administração pública. A título de referência pode-se citar e.g: artigos 10; 29; 31, §3ㅇ; 37,§3ㅇ, I, II, III; 74, §2o; 194 § único, VII; 198, III; 202, §6ㅇ; 204, II e outros.

Em que pese previsão constitucional dos dispositivos referidos, fato é que a grande maioria é relegada e até há pouco tempo se revelava pouco eficaz em decorrência da deficiente publicidade e da burocracia ao seu acesso e exercício, pois o cidadão em geral desconhece o conteúdo e as formas de instrumentalizar estes direitos participativos no Estado, o que inviabiliza sua atuação política efetiva. 
Este aparato normativo voltado para a participação efetiva do cidadão na administração pública no sentido de ter conhecimento prático das informações (cognoscibilidade) e auxiliar na fiscalização e boa aplicação de recursos públicos permanecia inerte na letra do texto constitucional pela inoperância da administração pública e sucessivos governos em promovê-los e divulgá-los (talvez com a exceção do usuário, na condição de consumidor, em reclamar da prestação de serviços públicos deficientes, artigo 37, §3으, I).

Compartilha deste entendimento Paulo Modesto (2005, p. 7), ao confirmar que existem vários procedimentos com amparo constitucional direto e outros com arrimo em regulação infraconstitucional, como os constantes da Lei de Normas Gerais de Processo Administrativo (Lei 9.784/99, v.g., artigos 31 a 34), mas que são indistintamente pouco utilizados e conhecidos.

Outrossim, existem também as barreiras burocráticas que dificultam o exercício destes direitos de participação, pois em regra o cidadão vivencia ou tem conhecimento sobre as dificuldades quanto ao acesso efetivo dos usuários aos registros administrativos e em obter informações sobre atos de governo mesmo com a promulgação da Lei n. 12.527, de 18 de novembro de 2011 (Lei de Acesso à Informação), voltada para dar transparência aos atos da administração pública, diploma que está à frente de nossos costumes públicos e administrativos.

Setores da administração pública criados pelo Estado Democrático de Direito para coibir abusos e voltados para a defesa do erário e do cumprimento da lei, ou seja, Tribunal de Contas, ${ }^{1}$ Ministério Público e Magistratura mostram-se recalcitrantes em prestar informações públicas conforme exige a Lei de Acesso à Informação, no que lhes toca organicamente.

Não devemos esquecer que os poderes políticos que integram a administração pública, respectivamente poder Executivo ${ }^{2}$ e Legislativo, ${ }^{3}$ também adotam muitas vezes o expediente de ocultar e dificultar o acesso às informações de interesse geral para conhecimento público e acabam sendo tolerantes uns com os outros em prejuízo da transparência das relações constituídos no seio dos poderes do Estado (sobre o que se passa no âmbito político-burocrático).

\footnotetext{
Conforme reportagem de Sergio Roxo, publicada em 16/5/2013, sob o título Maioria dos tribunais de contas descumpre Lei de Acesso. (...). "Levantamento realizado em sites dos tribunais das 27 unidades da Federação mostra que 16 não informam o salário de cada funcionário, como foi estabelecido pela regulamentação da Lei de Acesso à Informação, aplicada aos poderes Executivo, Legislativo e Judiciário. Além da falta de informação sobre os salários, alguns órgãos também não respeitam outras determinações da Lei de Acesso, como a publicação de uma ferramenta para que o usuário possa pedir informações. Dados de despesas e licitações, em muitos casos, também estão desatualizados. (...) A Lei de Acesso à Informação estabelece que esse tipo de dado deve ser disponibilizado em tempo real. (...) Os tribunais de Ceará, Pará, Paraná, Rondônia e Santa Catarina cumprem o modelo de transparência adotado pela União". Disponível em: http://oglobo.globo.com/pais/maioria-dostribunais-de-contas-descumpre-lei-de-acesso-8404774\#ixzz2bCokhNXd. Acesso em: 6 ago. 2017.

2 Reportagem de 9/11/2016: sob o título: A Farra dos Cartões Corporativos. Uma prática herdada do PT e que tem que ser combatida por Temer. Os cartões corporativos foram criados pelo governo de Fernando Henrique Cardoso, em 2001. Destinavam-se justamente a substituir as chamadas contas do "Tipo B". Antes, o servidor recebia dinheiro vivo, depositava em sua conta bancária e emitia cheques pessoais à medida que realizava os gastos. A mudança veio para dar mais transparência ao gasto público, facilitando a fiscalização. O problema é que a facilidade levou ao exagero (...). Disponível em:http:// www.noticiasbrasilonline.com.br/a-farra-dos-cartoes-corporativos-uma-pratica-herdada-pelo-pt-que-tem-que-ser-combatida-por-temer/. Acesso em: 6 set. 2017.

3 Sob o título Mais de 468 atos secretos são descobertos no Senado. Uma lista de 468 atos secretos surgiu na noite desta quarta-feira (12) no Senado. Foram emitidos há cerca de dez anos para nomeações, demissões e gratificações (...). A lista a que o "Jornal da Globo" teve acesso com exclusividade mostra a documentação para nomear e dispensar funcionários dos gabinetes, da gráfica e do serviço de processamento de dados do Senado. Entre 1998 e 1999, quando o falecido senador Antônio Carlos Magalhães era o presidente do Senado, os atos secretos foram incluídos em boletins suplementares, e só agora disponibilizados na rede de computadores do Senado, depois que a comissão de sindicância iria terminar o trabalho com os atos secretos anteriores (...). Conforme reportagem de 13/8/2009, do Jornal O Globo. Visitado em: 6/9/2017.
} 
Além dos emblemáticos casos jornalísticos exemplificados (em que informações requeridas foram negadas com base na Lei de Acesso à informação), fato é que embora os comandos constitucionais e legislação correlata estejam previstos, o desconhecimento e a deficiente divulgação e disponibilização das informações por parte do Estado, e por consequência, a dificuldade de acesso a estes dados pelos cidadãos, inviabilizavam a efetiva participação funcional da sociedade civil para auxiliar na fiscalização da administração pública, bem como coibir os abusos e descaminhos praticados por seus agentes.

Complementarmente, com a publicação do Decreto n. 9.094/2017 (que revogou a Ges-Pública Decreto n. 5378/2005), foi criado um canal digital (artigos 13 e 14, prevê o formulário on-line denominado Simplifique!) para o cidadão formular propostas para a simplificação dos serviços públicos (desburocratização) a fim de melhorar o acesso, a qualidade e a execução de serviços, com acompanhamento a cargo de Ouvidorias públicas para atendimento e retorno em até 30 dias.

O aludido Simplifique! possibilita em tese que os usuários possam sugerir melhorias, identifiquem falhas e questionem a exigência de documentos e procedimentos requeridos pelas repartições públicas. O objetivo é colaborar com a melhoria do atendimento aos usuários, reduzir o excesso de burocracia e gerar agilidade, economicidade e efetividade à administração pública, presumindo a participação ativa da sociedade em todo processo.

Não obstante o mérito da iniciativa, ao que parece o cidadão em geral ainda não teve amplo conhecimento deste novo mecanismo cívico e historicamente não tem o hábito de participar como cidadão na administração pública, pois até o momento são escassas as informações com relação aos resultados efetivos alcançados com o sistema de formulário eletrônico adotado, não obstante estar sujeito a críticas. ${ }^{4}$

\section{POSSIBILIDADES DE PARTICIPAÇÃO DEMOCRÁTICA DO CIDADÃO NO AMBIENTE DIGITAL}

Importante frisar que além do acesso aos serviços e bens públicos, a informações de interesse individual ou coletivo ou geral, a participação do cidadão tem por premissa a transparência e a publicidade dos registros públicos, na possibilidade de o cidadão ter amplo acesso a registros administrativos e informações sobre atos de governo e colaborar diretamente no controle e aperfeiçoamento dos atos administração pública.

\footnotetext{
4 DECRETO № 9.094, DE 17 DE JULHO DE 2017 DA DIVULGAÇÃO AOS USUÁRIOS DOS SERVIÇOS PÚBLICOS.

(...) Art. 18. A Carta de Serviços ao Usuário, a forma de acesso, as orientações de uso e as informações do formulário Simplifique! deverão ser objetos de permanente divulgação aos usuários dos serviços públicos, e mantidos visíveis e acessíveis ao público:

I- nos locais de atendimento;

II - nos portais institucionais e de prestação de serviços na Internet, a partir de link de acesso ao Portal de Serviços do Governo Federal.

5 Conforme reportagem de 25/1/2018, “Apesar da publicação do Decreto no 9.094/17 órgãos públicos continuam fazendo exigências desnecessárias. O Decreto no 9.094/17 proíbe os órgãos de exigir dos cidadãos atestados, certidões ou outros documentos que constem de uma base de dados oficial da administração pública. Órgãos como o DER do Estado de São Paulo continuam, por exemplo, exigindo cópia do CRLV dos veículos para concessão de AET". Disponível em: http://www. guiadotrc.com.br/noticias/noticialD.asp?id=33883. Acesso em: 13 mar. 2019.
} 
Nesta linha de raciocínio J. J. Gomes Canotilho (2002, p. 510) faz alusão ao "direito ao arquivo aberto" da Constituição Portuguesa de 1976 (artigo 268, 1ㅇ e 2ㅇ), a qual consagra a ideia de democracia administrativa para esclarecer que esse conceito não se resume a um direito de acesso aos arquivos e registros públicos para defesa de direitos individuais, mas também o direito de saber o que se passa no âmbito dos esquemas político-burocráticos.

Referido jurista português assevera que a amplitude comunicativa do "direito ao arquivo aberto" entre Estado e cidadãos deve ser ampla, pois:

O direito ao arquivo aberto deve hoje conceber-se não apenas como o direito a obter informações por parte dos cidadãos, mas também como direito a uma comunicação aberta entre as autoridades e os cidadãos. A comunicação aberta implicará, entre outras coisas, o dever de a administração fornecer activamente informações (ex.: colocar os dados informativos na Internet, criar sites adequados, ofertas on-line). A isso acresce o chamado dever de informação informada ou finalística que pode incluir informações indispensáveis para alicerçar o direito de acesso aos tribunais (...) (CANOTILHO, 2002, p. 510).

Ao partir da premissa de que a administração deve fornecer ativamente informações, aliada à utilização da Internet e a popularização das redes pelas instituições governamentais (embora grande parte da sociedade brasileira ainda sofra com a exclusão digital), ${ }^{6}$ inaugura-se nova possibilidade de exercício de cidadania, vez que a tecnologia cibernética contribui de forma decisiva para democratizar o acesso a informações e dados de interesse geral ou público ao privilegiar a comunicação aberta entre administração e administrados que a sociedade pretende lograr no sentido de materializar a publicidade e a transparência dos atos da administração pública (a rogo do artigo 3o, da Lei n. 12.527/2011).

Assim, os comandos normativos voltados para o desenvolvimento institucional e para o cidadão colaborar com a administração pública ganharam nova relevância com as tecnologias da comunicação ínsitas à sociedade da informação. Atualmente todo órgão da administração pública direta e indireta ligada aos três poderes tem obrigação legal (artigo 8o da Lei n. $12.527 / 2011)^{7}$ de possuir sites próprios e canais de interlocução digital diretos (Ouvidorias, SACs, Protocolos de Serviço, Denúncias) com a sociedade civil a fim de dar transparência a sua atuação e permitir que o cidadão tenha possibilidade de interlocução direta com estes órgãos.

A tecnologia disponível nestes últimos anos aliada a um ordenamento constitucional (e.g.: artigo 37, C.F.) e infraconstitucional (e.g.: Lei n. 12.527/2011, Lei n. 12.965/14, etc.) consentâneo com o mister permitem que a sociedade exija avanços institucionais do Estado quanto à transparência e responsabilização (accountability) dos órgãos da administração pública direta e indireta e de seus agentes.

\footnotetext{
KNIGHT, Peter T. A internet no Brasil - origens, estratégia, desenvolvimento e governança. Bloomington, Indiana, EUA: Authorhouse, 2014, p. 139: "A televisão continua a ser o meio de comunicação predominante no Brasil: $97 \%$ das casas tinham um aparelho de TV a cor em 2012, enquanto apenas 40\% tinham um computador com acesso à Internet".

7 Lei $12.527 / 2011$. (...)

Art. 8o - É dever dos órgãos e entidades públicas promover, independentemente de requerimentos, a divulgação em local de fácil acesso, no âmbito de suas competências, de informações de interesse coletivo ou geral por eles produzidas ou custodiadas.
} 
As mudanças atribuídas ao ambiente digital são perceptíveis no cotidiano do cidadão: na comunicação social ou profissional remota e instantânea; no acesso a informações diversas mediante buscas na Internet; na virtualização do Judiciário, com leilões, petições e verificação de processos eletrônicos junto aos Tribunais; no acesso a sites e serviços de parte dos órgãos públicos; na utilização de assinaturas digitais; faturas eletrônicas e comércio eletrônico em geral, etc.

Assim sendo, a exigência de avanços institucionais quanto à publicidade de seus atos e a transparência na atuação do Estado e seus agentes são demandas necessárias para os cidadãos em países democráticos no início do século 21. Mais que isso, o ambiente cibernético tem o condão de legitimar um processo de empoderamento do cidadão quanto ao seu "direito de saber" o que se passa no âmbito da administração e ter acesso (comunicação aberta) às informações relacionadas à atuação do Estado, bem como quanto aos mecanismos de aplicação e controle dos recursos do patrimônio público.

A publicidade dos atos oficiais e a transparência da administração pública ao prestar informações aos cidadãos quanto à aplicação e manejo dos recursos financeiros têm por objetivo possibilitar o sentido de pertença em um Estado democrático; reprimir condutas arraigadas a nossa histórica concepção política patrimonialista; combater instituições burocráticas oriundas de um Estado autoritário; exigir liberdade de acesso à informação e de socialização de atos de governo para conhecimento dos cidadãos.

Assim, é fundamental a disponibilização das informações com relação aos atos públicos para que a sociedade possa ter acesso, conhecimento e controle sobre os agentes investidos de função pública, pois, segundo Norberto Bobbio (2000, p. 102):

Entende-se que a maior ou menor relevância da opinião pública como opinião relativa aos atos públicos, isto é, aos atos próprios do poder público que é por excelência o poder exercido pelos supremos órgãos decisórios do Estado, da "res publica", depende da maior ou menor oferta ao público, entendida esta exatamente como visibilidade, cognoscibilidade, acessibilidade e, portanto, controlabilidade dos atos de quem detém o supremo poder.

Exsurge, portanto, como notável contribuição para os Estados democráticos que esteja disponível tecnologia compatível para promover o acesso a todas as informações da administração pública direta e indireta, de interesse individual ou geral disponível e publicadas para a análise e verificação da sociedade civil, tanto para permitir o controle da boa aplicação dos recursos como para discutir as prioridades dos administradores na utilização dos recursos e exigir melhores serviços em prol da sociedade.

\section{CIBERCIDADANIA E A PARTICIPAÇÃO DEMOCRÁTICA NO ESTADO BRASILEIRO}

Como corolário do acesso às informações disponibilizadas em rede e por meio da Internet no tocante à administração pública neste início de século 21 , Antonio Henrique Pérez Luño (2004) reconhece o desenvolvimento do que denomina de cibercidadania e de cibertransparência como possibilidades de exercício de novas relações democráticas entre administração e administrados. Assim, em sua conceituação: 
Cibercidadania: expressão que traduz uma nova forma de a administração pública disponibilizar a informação em rede aos cidadãos, que pode não ser somente a utilização da ferramenta tecnológica, mas uma nova forma de gerenciamento público e das relações democráticas com a sociedade, que daí advenham;

(...)

e a cibertransparência, que ao otimizar a gestão dos recursos públicos contribui para a tutela real e efetiva dos direitos sociais. Não se pode esquecer que a garantia eficaz dos direitos sociais exige a criação de serviços públicos e de prestações e esses instrumentos de garantia dependem diretamente de um uso adequado e eficiente dos recursos públicos (PÉREZ LUÑO, p. 2-3 prefácio de obra, LIMBERGER, 2016).

Depreende-se que a ampla disponibilização de informações de interesse público por meio do ambiente digital estabelece novos pontos de contato entre os cidadãos e o Estado ao favorecer a administração eletrônica encarregada de disseminar dados de sua atuação e possibilitar o acompanhamento e fiscalização pelos cidadãos, bem como melhorar o acesso aos seus representantes, contribuindo inclusive para a tutela de direitos sociais.

Consoante esclarece Manuel Castells (1999, p. 412), o informacionalismo é a base material da atual sociedade, em que a geração de riquezas e o exercício do poder passaram a depender da capacidade tecnológica dos indivíduos, sendo a tecnologia da informação o elemento mediador, a ferramenta indispensável para a instituição efetiva dos processos de reestruturação socioeconômica, aí incluído o funcionamento da administração pública com auxílio dos cidadãos.

Assim, todos os possíveis processos de reestruturação econômica, social e institucional na era da sociedade da informação permeados pela utilização do aparato tecnológico e funcional pela administração pública, têm relação de causa-efeito com a velocidade de circulação, armazenamento e disponibilização da informação no tocante à dinâmica com que as decisões de governos democráticos são construídas, verificadas e prestadas as contas; e, também, a capacidade de organização e acompanhamento pela sociedade destas mesmas decisões que envolvam opções políticas e aplicação eficiente de recursos públicos (LEVY, 2015, p. 79).

Na complementação de Gustavo Cardoso (1999, p. 116), a tecnologia atualmente existente permite flexibilidade, uma vez que a rede digital pode ser instalada em todos os tipos de processo e organizações produtivas e as instituições podem ser reconfiguradas e modificadas física e funcionalmente com a utilização das tecnologias da informação.

A infraestrutura eletrônica, além de conferir ganhos de eficiência graças a dispositivos alimentados por cabos de fibra ótica e conexões de alta velocidade remota (wi-fi), pode ser usada estrategicamente para priorizar a publicidade e a transparência das informações, permitir o acompanhamento em tempo real dos atos de governo e atacar os problemas institucionais ligados a práticas deletérias de justificar decisões enviesadas em nome do interesse público à revelia da sociedade (KNIGHT, 2014, p. 138).

Tem a acrescentar Têmis Limberger (2016, p. 83-84) que entre os predicados da ampla veiculação pelo Estado de informações de interesse público pelos meios telemáticos está também a inibição da corrupção na administração pública diante da ampla publicidade possibilitada pela Internet, notadamente quando comparado com os métodos tradicionais de veiculação de publicações em Diários Oficiais. 


\section{Humanos}

Democracia

Neste aspecto, é tarefa estratégica dos Estados contemporâneos aperfeiçoarem os mecanismos institucionais a fim de estabelecer uma administração pública eficiente na prestação de serviços essenciais com a utilização das tecnologias disponíveis para respeitar a publicidade dos atos oficiais, prestar contas e adotar mecanismos de cibertransparência na forma preconizada pela legislação infraconstitucional (Lei n. 12.527/2011 e Lei n. 12.965/14), como forma de promover a gestão da coisa pública em colaboração com a sociedade.

É papel da adminstração pública fomentar, outrossim, relação de reciprocidade com os cidadãos, notadamente pela instituição de serviços de informação em rede, acessíveis em todos os níveis da administração pública por meio das tecnologias digitais democratizantes e participativas a fim de melhorar o gerenciamento público e aproximar o cidadão (cibercidadania) do Estado, para que colabore no seu desenvolvimento democrático.

No tocante, contudo, à relação de reciprocidade entre administração pública e cidadão, importante reconhecer que não obstante o arcabouço normativo referido e a tecnologia em rede disponível há uma dimensão sociológica a demonstrar que persiste grande insatisfação da sociedade brasileira com relação ao funcionamento do Estado.

Recente pesquisa do ICJBrasil ${ }^{8}$ de 2017 revela queda na confiança da população em praticamente todas as instituições analisadas, concluindo que a instituição menos confiável por parte da sociedade é exatamente o Estado brasileiro (governo federal), com apenas $6 \%$ de credibilidade.

Persiste uma cultura política não colaborativa dos brasileiros, advindo com isso insatisfação do cidadão com o funcionamento concreto de instituições como o Estado e demais descentralizações da administração pública e, por consequência, baixa adesão ao regime democrático delineado pela Constituição de 1988 (SWENSSON JR., 2018, p. 51-52), ${ }^{9}$ independentemente da disponibilização dos meios tecnológicos telemáticos e da legislação que Ihe dá guarida.

Esse panorama fático ajuda a explicar o baixo interesse e a restrita participação popular na gestão administrativa no Estado, inobstante os mecanismos cibernéticos disponíveis e amparados em legislação correlata, diante de sentimento negativo da sociedade com o funcionamento da democracia e a baixa confiança de que gozam nossas instituições. ${ }^{10}$

\footnotetext{
8 Publicado em 24 de outubro 2017, ICJBrasil 2017: Confiança da população nas instituições cai. As instituições que mais tiveram queda no seu grau de confiança foram o governo federal, que passou de $29 \%$ para $6 \%$, o Ministério Público, de $50 \%$ para $28 \%$, e as grandes empresas, cuja confiança passou de $43 \%$ para $29 \%$. Disponível em: https://portal.fgv.br/noticias/ icjbrasil-2017-confianca-populacao-instituicoes-cai. Acesso em: 13 mar. 2019.

9 Reportagem de 27/10/2017. Pesquisa aponta que brasileiros são os que menos confiam em democracia na América Latina. Uma pesquisa realizada em 18 países da América Latina revelou que os brasileiros são os mais insatisfeitos com a democracia. Somente $13 \%$ dos brasileiros responderam estar "muito satisfeitos" e "satisfeitos" com ela, segundo o levantamento da Latinobarómetro. Disponível em: https://www.bbc.com/portuguese/brasil-41780226. Acesso em: 13 mar. 2019.

${ }^{10}$ Nos termos do Informe 2018, do Latinobarómetro, p. $54-55$ (tradução livre do original em espanhol): “Os três países com menos confiança no governo são: Brasil, que é de apenas 7\%, El Salvador, 10\% e Peru, 13\%. (...) Nenhum desses números é motivo de elogios ou aplausos. Os níveis de confiança caem na América Latina, independentemente da instituição ou país. Não há nada além de perda de legitimidade das instituições da democracia nos últimos anos. Países que têm menor grau de confiança são mais vulneráveis, sem dúvida. O caso do Brasil é emblemático, tem as menções mais baixas, incluindo as de confiança". Disponível em: file:///C:/Users/Dr.\%20Caio\%20Sperandeo/Documents/INFORME_2018_LATINOBAROMETRO.pdf. Acesso em: 20 mar. 2019.
} 
Esta é uma reflexão importante para o Estado brasileiro desenvolver formas educativas e interativas (com auxílio dos mecanismos telemáticos e tradicionais) a serem inseridas no sistema educacional para fomentar os mecanismos de participação funcional da sociedade civil para auxiliar na fiscalização da administração pública, bem como coibir os abusos e descaminhos praticados, diante da necessidade de participação do cidadão para o desenvolvimento da democracia participativa expressa na Carta Constitucional 1988.

\section{CONCLUSÃO}

Verificam-se avanços quanto à disponibilização de informações em rede prestadas pela administração pública especialmente em decorrência da utilização das novas tecnologias digitais (Internet) ínsitas à sociedade da informação, bem como da obrigatoriedade legal para que instituições governamentais publiquem informações e dados de interesse geral em seus sites, configurando o que se pode denominar de cibertransparência.

O ambiente cibernético tem o condão de estimular a cibercidadania, que se materializa no sentimento de empoderamento do cidadão sobre o que se passa no âmbito da administração pública com relação aos atos praticados por quem exerce poder em nome do Estado, de ter acesso a informações padronizadas do Estado, de acompanhar e fiscalizar os mecanismos de aplicação (cognoscibilidade e controlabilidade).

As novas tecnologias da comunicação disponíveis possibilitam a adoção de uma democracia administrativa transparente na prestação de serviços públicos aos cidadãos, que respeite a publicidade dos atos oficiais, que preste contas da sua gestão, que coíba a corrupção e que cobre responsabilidade em todos os níveis de governo.

Necessário reconhecer que os recursos cibernéticos ligados à tecnologia da informação e da comunicação e a legislação correlata, embora indispensáveis, são insuficientes para gerar de per se o engajamento cívico para o funcionamento concreto da democracia participativa no país.

Cabe ao Estado brasileiro desenvolver processos educativos em seu sistema de ensino para esclarecer e fomentar os mecanismos de participação funcional da sociedade civil a fim colaborar com o aperfeiçoamento do Estado democrático, renovando-se a confiança em suas instituições.

\section{REFERÊNCIAS}

ALEXY, Robert. Teoria dos Direitos Fundamentais. 2. ed. Tradução Virgílio Afonso da Silva. São Paulo: Malheiros, 2014.

BOBBIO, Norberto. O futuro da democracia. Tradução Marco Aurélio Nogueira. São Paulo, Paz e Terra, 2000. BONAVIDES, Paulo. Curso de Direito Constitucional. 16. ed. São Paulo: Malheiros Editores, 2005.

BRASIL. Constituição da República Federativa do Brasil 1988. 19. ed. Brasília: Câmara dos Deputados; Centro de Documentação e Informação Coordenação de Publicações, 2002.

CANOTILHO. J. J. Gomes. Direito Constitucional e Teoria da Constituição. 6. ed. Coimbra: Almedina, 2002.

CARDOSO, Gustavo. As causas das questões ou o Estado à beira da sociedade da informação. Sociologia - Problemas e Práticas, n. 30, 1999. Disponível em: http://www.bocc.ubi.pt/pag/cardoso-gustavo-causas-questoes.pdf.

CASTELLS, Manuel. A era da informação: economia, sociedade e cultura. Fim do Milênio. São Paulo: Paz e Terra, 1999. Vol. III.

DA SILVA, José Afonso. O sistema representativo, democracia semidireta e democracia participativa. Revista do Advogado, ano XXIII, n. 73, nov. 2003. 


\section{Humanos e \\ Democracia}

DA SILVA, José Afonso. Comentário contextual à Constituição. 5. ed. São Paulo: Malheiros, 2008.

FIORILLO, Celso Antonio Pacheco. Princípios Constitucionais do Direito na sociedade da informação; a tutela jurídica do meio ambiente digital. São Paulo: Saraiva 2015.

KNIGHT, Peter T. A internet no Brasil - origens, estratégia, desenvolvimento e governança. Bloomington, Indiana, EUA: Authorhouse, 2014.

LÉVY, Pierre. A inteligência coletiva. Por uma antropologia do ciberespaço. Tradução Luiz Paulo Rouanet. São Paulo: Folha de São Paulo, 2015.

LIMBERGER, Temis. Cibertransparência - informação pública em rede a virtualidade e suas repercussões na realidade. Porto Alegre: Livraria do Advogado, 2016.

MODESTO, Paulo. Participação popular na administração pública: mecanismos de operacionalização. Revista Eletrônica de Direito do Estado, Salvador: Instituto de Direito Público da Bahia, n. 2, abr./maio/jun. 2005.

PÉREZ LUÑO, Antonio Henrique.Ciberciudadani@ o ciudadani@.com? Barcelona: Gedia. 2004.

SWENSSON JR., Lauro Joppert. Notas sobre a Constituição transformadora democratizante. Revista do Advogado, ano XXXVIII, n. 140, nov. 2018.

\section{Referências digitais disponíveis em:}

http://www.direitodoestado.com/revista/rede-2-abril-2005-paulo\%20modesto.pdf. Acesso em: 10 set. 2017. http://oglobo.globo.com/pais/maioria-dos-tribunais-de-contas-descumpre-lei-de-acesso-8404774\#ixzz2bCokhNXd. Acesso em: 6 ago. 2017.

http://veja.abril.com.br/blog/ricardo-setti. Acesso em: 12 mar. 2017.

http://cgi.br/media/docs/publicacoes/1/CadernosCGlbr_DocumentosCMSI.pdf. Acesso em: 14 set. 2017.

http://bocc.ubi.pt/pag/cardoso-gustavo-causas-questoes.html. Acesso em: 14 set. 2017.

http://www.ip.pbh.gov.br/ANO4_N2_PDF/ip0402afonso.pdf. Acesso em: 21 mar. 2017.

http://www.noticiasbrasilonline.com.br/a-farra-dos-cartoes-corporativos-uma-pratica-herdada-pelo-pt-que-tem-que-ser-combatida-por-temer/. Acesso em: 7 abr. 2017.

https://portal.fgv.br/noticias/icjbrasil-2017-confianca-populacao-instituicoes-cai. Acesso em: 13 mar. 2019. https://www.bbc.com/portuguese/brasil-41780226. Acesso em: 13 mar. 2019.

file:///C:/Users/Dr.\%20Caio\%20Sperandeo/Documents/INFORME_2018_LATINOBAROMETRO.pdf. Acesso em: 20 mar. 2019. 